\title{
An experimental analysis and optimization of machining rate and surface characteristics in WEDM of Monel-400 using RSM and desirability approach
}

\author{
Vinod Kumar • Vikas Kumar • Kamal Kumar Jangra
}

Received: 30 September 2014/ Accepted: 6 February 2015/Published online: 17 March 2015

(C) The Author(s) 2015. This article is published with open access at Springerlink.com

\begin{abstract}
In the present work, an experimental investigation on wire electrical discharge machining (WEDM) of Monel-400 has been presented. Monel-400 is a nickelcopper-based alloy, mostly employed in ships and corrosion-resisting applications. Four input WEDM parameters namely discharge current (Ip), pulse-on time (Ton), pulseoff time (Toff) and servo voltage (SV) have been investigated and modeled for two performance characteristics namely machining rate (MR) and surface roughness (SR). Effect of WEDM parameters has been discussed using response surface graphs. Using analysis of variance, quadratic model is found significant for MR while two factors interaction $(2 \mathrm{FI})$ model has been suggested for SR. To optimize multi-performance characteristics, desirability function has been employed. Corresponding to highest desirability, the optimal combination of discharge parameters is Ip: $103 \mathrm{~A}$; Ton: $113 \mu \mathrm{s}$; Toff: $37 \mu$ s and SV: $50 \mathrm{~V}$. The effect of discharge energy on surface morphology has also been examined. High discharge energy increases the extent of surface damage and results in large size and overlapped craters on machined surface. Low discharge energy and high value of Toff result in minimum defects on machined surface. Trim cutting operations were
\end{abstract}

Vinod Kumar ( $\square)$

Department of Mechanical Engineering, YMCA University of Science and Technology, Faridabad, India

e-mail: vinodrohilla78@gmail.com

Vikas Kumar

Department of Mechanical Engineering, YMCA University of Science and Technology, Faridabad, India

K. K. Jangra

Department of Mechanical Engineering, PEC University

of Technology, Chandigarh, India performed at low discharge energy using different wire offset values. Result shows that surface finish can be improved significantly after a single trim cut irrespective of high discharge energy in rough cut.

Keywords Wire electrical discharge machining (WEDM) · Monel-400 - Response surface methodology (RSM) · Machining rate $\cdot$ Surface characteristics $\cdot$ Process optimization - Trim cutting operation

\section{Introduction}

Monel-400 is a solid solution of nickel and copper, having high strength and toughness over a wide temperature range. Because of its high resistance to corrosive and most acidic environment, Monel has been widely used in chemical industries, food processing industry, heat exchanger tubing, nuclear reactors, sub-marine and ship propellers, etc. (Shoemaker and Smith 2006).

Surface integrity of a machined component significantly affects its performance such as fatigue life, creep and corrosion. Surface integrity of a machined component may include residual stresses, recast layer, heat-affected zone and microcracks (Klink et al. 2011). In past, several investigations have been carried out for machining performance of nickel-based alloys except Monel, with conventional and non-conventional machining processes. Due to high heat-resisting capacity, nickel-based alloys are very difficult to machine with conventional machining processes such as milling, turning and drilling (Wei 2002; Sharman et al. 2006; Krain et al. 2007; Soo et al. 2011; Hood et al. 2011; Antar et al. 2011). Machining of nickel alloys using conventional cutting tools results in the formation of built-up edge on tool face and high tendency of 
welding to the tool, resulting in large crater wear and poor surface integrity involving several surface defects such as surface drag, material pull-out/cracking and tearing surface. (Ulutan and Ozel 2011; Kortabarria et al. 2011; Herbert et al. 2012).

Wire electrical discharge machining (WEDM) can be proved more economic and efficient for machining complex and intricate profiles in high strength and high heatresisting materials. In WEDM, material is removed by melting and vaporization through high localized heat generation by repetitive sparks occurring between conductive work material and wire electrode separated by dielectric fluid which carries away the eroded particles. In past, some investigations have been carried out on machining of nickel alloys with EDM or WEDM. But most of earlier investigations evaluated the machining of Inconel grade of nickel alloys (In-718, In-601 etc.). Kang and Kim (2003) investigated the EDM characteristics of nickelbased heat resistance alloy Hastelloy-X. Pulse-on time was the main factor that affect the surface integrity of the work material. Hewidy et al. (2005) correlated the various WEDM parameters such as peak current, duty factor, wire tension, and water pressure with the performance outputs namely metal removal rate (MRR), wear ratio and surface roughness in WEDM of Inconel 601. Liu et al. (2005) investigated the significant machine parameters which are affecting the characteristics of microholes in nickel alloy in terms of microhole expansion, electrode depletion and material removal rate. A proper discharge current is very important to achieve optimum results. Aspinwall et al. (2008) presented roughing and finishing strategies for machining of Ti-6Al-4 V and Inconel 718 on WEDM. The average recast layer thickness less than $11 \mu \mathrm{m}$ was found in rough cut and after trim passes apparently no recast layer was obtained.

Previous investigations show that the discharge current and pulse-on time are the most important parameters in WEDM that significantly affect the material removal rate and surface characteristics of the machined component (Shivade and Shinde 2014). To obtain high material removal rate, high discharge energy is required which results in high heat generation across the work material and wire electrode. But high heat generation results in poorer surface integrity including large recast layer, heat-affected zone and several microcracks (Klink et al. 2011; Rebelo et al. 1998). The main cause of poor surface integrity is due to either re-solidification of melted materials on the machined surface or generation of high-pressure energy in plasma channel across the electrodes ( $\mathrm{Li}$ et al. 2013). Using trim cuts, damaged surface layer can be removed and surface integrity can be improved significantly (Jangra 2012, 2014; Sakar et al. 2008; Sanchez et al. 2007).
In the present work, machining performance of Monel400 has been evaluated on WEDM. Four important parameters have been investigated and modeled for machining rate (MR) and surface roughness (SR) using response surface methodology (RSM). RSM is the most used statistical technique for determining the relationship between various input parameters and output responses (Hewidy et al. 2005; Myers and Montgomery 1995; Jangra and Grover 2012). Using face-centered central composite design, experimental data were obtained to develop mathematical models for input variables and output machining characteristics. Influence of discharge energy on surface morphology has been compared using micrograph of machined surface and microhardness profiles. After modeling the machining characteristics in rough cutting operation, trim cutting operations have been performed at low discharge energy and different wire offset values to examine the effect of trim cut on final surface finish of the work material.

\section{Experimentation}

In the present work, experiments were performed on 5-axis sprint cut (ELPUSE-40) wire EDM manufactured by Electronica M/C Tool LTD India. Monel-400, a nickelbased alloy containing $63 \% \mathrm{Ni}, 33 \% \mathrm{Cu}, 2.13 \% \mathrm{Fe}$, and $1 \% \mathrm{Mn}$, hot forged in rectangular sheet of $12.5 \mathrm{~mm}$ thickness, has been selected as workpiece material. Using WEDM, work material was machined and samples were obtained in the form of rectangular punch of dimension $5 \mathrm{~mm} \times 6 \mathrm{~mm} \times 12.5 \mathrm{~mm}$.

In rough cutting operation, only discharge parameters namely discharge current (Ip), pulse-on time (Ton), pulseoff time (Toff) and servo voltage (SV) have been selected as variable parameters while parameters under the category of wire electrode and dielectric conditions have been assigned a constant value. Zinc-coated brass wire having a fixed diameter of $0.25 \mathrm{~mm}$ has been selected as wire electrode. In WEDM, wire feed rate should be kept at low value to minimize the machining cost. Therefore, a constant value of $5 \mathrm{~m} / \mathrm{min}$ has been assigned to wire feed rate with adequate value of $10 \mathrm{~N}$ of wire tension. Experiments for rough cutting operation were conducted at zero wire offset value. Distilled water having conductivity 20 mho has been utilized in the present study. High flow rate of dielectric results in complete and quick flushing of the melted debris out of the spark gap which results in high machining rate and good surface finish. Therefore, dielectric flow rate was kept at high value of 12 liters per minute $\left(\mathrm{LM}^{-1}\right)$. Range and levels of four variable parameters have been listed in Table 1. 
Table 1 Variable parameters and their levels

\begin{tabular}{llllll}
\hline Symbol & Parameter & Units & Levels & \\
\cline { 5 - 5 } & & & Low $(-1)$ & Middle (0) & High $(+1)$ \\
\hline A & Discharge current (Ip) & $\mathrm{A}$ & 90 & 120 & 150 \\
$\mathrm{~B}$ & Pulse-on time (Ton) & $\mu \mathrm{s}$ & 106 & 112 & 118 \\
$\mathrm{C}$ & Pulse-off time (Toff) & $\mu \mathrm{s}$ & 35 & 40 & 45 \\
$\mathrm{D}$ & Servo voltage (SV) & $\mathrm{V}$ & 30 & 40 & 50 \\
\hline
\end{tabular}

MR was measured in $\mathrm{mm} / \mathrm{min}$ which was observed directly from machine tool monitor screen. SR value (in $\mu \mathrm{m}$ ) was measured in terms of mean absolute deviation (Ra) using the digital surface tester Mitutoyo 201P. SEM images were obtained through SEM equipment (JSM-6610 LV) manufactured by JEOL USA Inc, USA.

\section{Results and discussions}

Response surface methodology (RSM) is a collection of mathematical and experimental techniques that requires sufficient number of experimental data to analyze the problem and to develop mathematical models for several input variables and output performance characteristics (Myers and Montgomery 1995; Kansal et al. 2005). Using the design of experiments and applying regression analysis, the modeling of the desired response $(Y)$ to several independent input variables $\left(x_{i}\right)$ can be gained. In RSM, the quantitative form of relationship between desired response and independent input variables could be represented as:

$Y=\Phi\left(x_{1}, x_{2}, \ldots \ldots \ldots \ldots, x_{k}\right) \pm e_{r}$.

The function $\Phi$ is called response surface or response function. The residual $e_{r}$ measures the experimental errors (Cochran and Cox 1962).

By applying the RSM, the dependent variable is viewed as a surface to which a mathematical model is fitted. For the development of regression equations related to various performance characteristics of WEDM process, the secondorder response surface has been assumed as:

$Y=b_{0}+\sum_{i=1}^{k} b_{i} X_{i}+\sum_{i=1}^{k} b_{\mathrm{ii}} X_{i}^{2}+\sum_{i<j=2}^{2} b_{\mathrm{ij}} X_{i} X_{j} \pm e_{r}$

This assumed surface $Y$ contains linear, squared and cross-product terms of variables $X_{i}^{\prime} s$. The model parameters can be estimated most effectively if proper experimental designs are used to collect the data.

In the present study, four numerical variables are set at three levels. Therefore, a standard second-order experimental design called face-centered central composite design (CCD) has been adopted for analyzing and modeling the WEDM parameters for MR and SR. This design consists of full factorial having 30 runs including 6 central points. The center points, as implied by the name, all levels set to the midpoint of each parameter range. Based on the experimental layout shown in Table 2, the experiments were performed and two machining characteristics were measured.

The regression equation for output machining characteristics (MR and SR) and input parameters can be obtained using generalized Eq. (2) and experimental data in Table 2. But in the present case, design expert (DX-7), a statistical tool is used to generate the regression equation for MR in coded and actual terms as given in Eqs. 3 and 4. Analysis of variance (ANOVA) has been performed on the experimental data to test the goodness of fit of the model. This includes the test for significance of the regression model, test for significance on model coefficients and test for lack-of-fit model adequacy.

Analysis of machining rate (MR)

Fit summary for MR, after backward elimination process, has been listed in Table 3. Using backward elimination process, insignificant terms $(p$ value $>0.05)$ have been eliminated from the reduced quadratic model. Table 3 shows that $p$ value for quadratic model is significant which shows that the terms in the model have significant effect on output response. In the present case, the value of $R^{2}$ and $R^{2}$ (adj.), called coefficient of determination, is over $99 \%$. When $R^{2}$ approaches unity, the better the response model fits the actual data. Also, test of 'lack of fit' shows insignificant effect, which is desirable for selecting the models (Kansal et al. 2005). Figure 1 shows that the residuals are normally distributed about a straight line which means that the errors are normally distributed. The final response equation for MR is given as follows:

In coded terms:

$$
\begin{aligned}
\mathrm{MR} & =2.50+0.11 \mathrm{~A}+0.72 \mathrm{~B}-0.19 \mathrm{C}-0.16 \mathrm{D} \\
& -0.12(\mathrm{~A})^{2}-0.36(\mathrm{~B})^{2}-0.078(\mathrm{C})^{2}+0.057(\mathrm{D})^{2} \\
& +0.031 \mathrm{~A} \times \mathrm{B}+0.046 \mathrm{~B} \times \mathrm{C} .
\end{aligned}
$$


Table 2 Test conditions in face-centered central composite design for four parameters

\begin{tabular}{|c|c|c|c|c|c|c|c|c|c|c|}
\hline Trial no. & Ip (A) & Coded value & Ton $(\mu s)$ & Coded value & Toff $(\mu s)$ & Coded value & SV (V) & Coded value & $\mathrm{MR}(\mathrm{mm} / \mathrm{min})$ & $\mathrm{SR}(\mu \mathrm{m})$ \\
\hline 1 & 90 & -1 & 106 & -1 & 35 & -1 & 30 & -1 & 1.60 & 1.33 \\
\hline 2 & 150 & 1 & 106 & -1 & 35 & -1 & 30 & -1 & 1.78 & 1.69 \\
\hline 3 & 90 & -1 & 118 & 1 & 35 & -1 & 30 & -1 & 2.86 & 2.21 \\
\hline 4 & 150 & 1 & 118 & 1 & 35 & -1 & 30 & -1 & 3.16 & 2.60 \\
\hline 5 & 90 & -1 & 106 & -1 & 45 & 1 & 30 & -1 & 1.12 & 1.11 \\
\hline 6 & 150 & 1 & 106 & -1 & 45 & 1 & 30 & -1 & 1.30 & 1.20 \\
\hline 7 & 90 & -1 & 118 & 1 & 45 & 1 & 30 & -1 & 2.60 & 1.98 \\
\hline 8 & 150 & 1 & 118 & 1 & 45 & 1 & 30 & -1 & 2.89 & 2.20 \\
\hline 9 & 90 & -1 & 106 & -1 & 35 & -1 & 50 & 1 & 1.28 & 1.12 \\
\hline 10 & 150 & 1 & 106 & -1 & 35 & -1 & 50 & 1 & 1.39 & 1.33 \\
\hline 11 & 90 & -1 & 118 & 1 & 35 & -1 & 50 & 1 & 2.57 & 1.78 \\
\hline 12 & 150 & 1 & 118 & 1 & 35 & -1 & 50 & 1 & 2.88 & 2.16 \\
\hline 13 & 90 & -1 & 106 & -1 & 45 & 1 & 50 & 1 & 0.79 & 0.98 \\
\hline 14 & 150 & 1 & 106 & -1 & 45 & 1 & 50 & 1 & 0.97 & 1.14 \\
\hline 15 & 90 & -1 & 118 & 1 & 45 & 1 & 50 & 1 & 2.30 & 1.68 \\
\hline 16 & 150 & 1 & 118 & 1 & 45 & 1 & 50 & 1 & 2.54 & 1.93 \\
\hline 17 & 90 & -1 & 112 & 0 & 40 & 0 & 40 & 0 & 2.29 & 1.54 \\
\hline 18 & 150 & 1 & 112 & 0 & 40 & 0 & 40 & 0 & 2.46 & 1.81 \\
\hline 19 & 120 & 0 & 106 & -1 & 40 & 0 & 40 & 0 & 1.40 & 1.20 \\
\hline 20 & 120 & 0 & 118 & 1 & 40 & 0 & 40 & 0 & 2.86 & 2.11 \\
\hline 21 & 120 & 0 & 112 & 0 & 35 & -1 & 40 & 0 & 2.64 & 1.79 \\
\hline 22 & 120 & 0 & 112 & 0 & 45 & 1 & 40 & 0 & 2.19 & 1.55 \\
\hline 23 & 120 & 0 & 112 & 0 & 40 & 0 & 30 & -1 & 2.73 & 1.83 \\
\hline 24 & 120 & 0 & 112 & 0 & 40 & 0 & 50 & 1 & 2.37 & 1.52 \\
\hline 25 & 120 & 0 & 112 & 0 & 40 & 0 & 40 & 0 & 2.50 & 1.64 \\
\hline 26 & 120 & 0 & 112 & 0 & 40 & 0 & 40 & 0 & 2.51 & 1.68 \\
\hline 27 & 120 & 0 & 112 & 0 & 40 & 0 & 40 & 0 & 2.50 & 1.69 \\
\hline 28 & 120 & 0 & 112 & 0 & 40 & 0 & 40 & 0 & 2.53 & 1.67 \\
\hline 29 & 120 & 0 & 112 & 0 & 40 & 0 & 40 & 0 & 2.54 & 1.68 \\
\hline 30 & 120 & 0 & 112 & 0 & 40 & 0 & 40 & 0 & 2.51 & 1.69 \\
\hline
\end{tabular}

In actual terms:

$$
\begin{aligned}
\mathrm{MR}= & -132.79107+0.016153 \mathrm{Ip}+2.30068 \text { Ton } \\
& -0.042170 \text { Toff }-0.061652 \mathrm{SV}-1.31579 \mathrm{E} \\
& -004(\mathrm{Ip})^{2}-0.010095(\text { Ton })^{2}-3.13684 \mathrm{E} \\
& -003 \text { Toff }^{2}+5.65789 \mathrm{E}-004 \mathrm{SV}^{2}+1.70139 \mathrm{E} \\
& -004 \text { Ip } \times \text { Ton }+1.52083 \mathrm{E}-003 \text { Ton } \times \text { Toff. }
\end{aligned}
$$

\section{Effect of WEDM parameters on MR}

To analyze the effect of WEDM parameters on MR, response surface graphs have been plotted as shown in Fig. 2a-c. Reponse surface graph shows that the machining rate increases with increasing value of Ton and Ip. Effect of pulse-on time is highly significant as compared to discharge current. Increasing Ip and Ton increases the discharge energy across the electrode and hence results in high melting and evaporation of material. High melting and evaporation combined with high dielectric supply result in high machining rate (Jangra and Grover 2012). Machining rate decreases with increase in value of Toff from 35 to $45 \mu$ s as shown in Fig. 2b, c. Increasing pulse-off time decreases the effective discharge frequency and hence decreases the discharge energy across the electrodes resulting in low machining rate.

Servo voltage (SV) controls the discharge gap across the wire electrode and work surface. Decreasing servo voltage results in narrow spark gap which results in large ionization of spark gap and hence more melting of work material, as a result machining rate increases as shown in Fig. 2c. Highest machining rate is obtained corresponding to Ton: $118 \mu \mathrm{s} ; \mathrm{Ip}$ : 
Table 3 ANOVA table for fitted model for MR

\begin{tabular}{|c|c|c|c|c|c|c|}
\hline \multirow{2}{*}{$\frac{\text { Source }}{\text { Model }}$} & \multirow{2}{*}{$\frac{\text { Sum of squares }}{12.47}$} & \multirow{2}{*}{$\begin{array}{l}\text { Degree of freedom } \\
10\end{array}$} & \multirow{2}{*}{$\begin{array}{l}\text { Mean square } \\
1.25\end{array}$} & \multirow{2}{*}{$\frac{F \text { value }}{1797.41}$} & \multicolumn{2}{|l|}{$p$ value } \\
\hline & & & & & $<0.0001$ & Significant \\
\hline A & 0.21 & 1 & 0.21 & 307.56 & $<0.0001$ & \\
\hline B & 9.43 & 1 & 9.43 & 13592.64 & $<0.0001$ & \\
\hline $\mathrm{C}$ & 0.67 & 1 & 0.67 & 958.44 & $<0.0001$ & \\
\hline $\mathrm{D}$ & 0.48 & 1 & 0.48 & 696.72 & $<0.0001$ & \\
\hline $\mathrm{A}^{2}$ & 0.036 & 1 & 0.036 & 52.36 & $<0.0001$ & \\
\hline $\mathrm{B}^{2}$ & 0.34 & 1 & 0.34 & 493.13 & $<0.0001$ & \\
\hline $\mathrm{C}^{2}$ & 0.016 & 1 & 0.016 & 22.96 & $<0.0001$ & \\
\hline $\mathrm{D}^{2}$ & $8.29 \mathrm{E}-003$ & 1 & $8.294 \mathrm{E}-003$ & 11.95 & 0.0026 & \\
\hline $\mathrm{AB}$ & 0.015 & 1 & 0.015 & 21.63 & 0.0002 & \\
\hline $\mathrm{BC}$ & 0.033 & 1 & 0.033 & 48.00 & $<0.0001$ & \\
\hline Residual & 0.013 & 19 & $6.939 \mathrm{E}-004$ & & & \\
\hline Lack of fit & 0.012 & 14 & $8.453 \mathrm{E}-004$ & 3.13 & 0.1069 & Not significant \\
\hline Pure error & $1.350 \mathrm{E}-003$ & 5 & $2.700 \mathrm{E}-004$ & & & \\
\hline Cor total & 12.49 & 29 & & & & \\
\hline \multicolumn{2}{|c|}{ Standard deviation $=0.026$} & $R^{2}=0.9989$ & \multicolumn{4}{|c|}{$R^{2}($ Adj. $)=0.9984$} \\
\hline
\end{tabular}

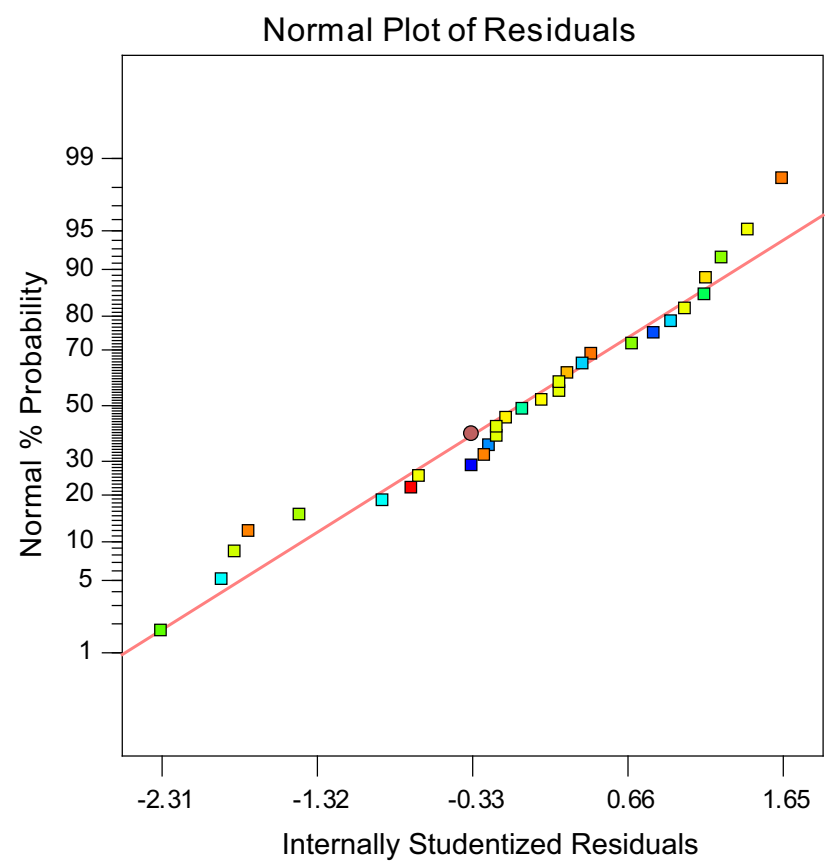

Fig. 1 Residuals plot for MR

150 A; Toff: $35 \mu \mathrm{s}$; SV: $30 \mathrm{~V}$. Increasing the value of Ton, Ip and decreasing Toff and SV beyond these limits, discharge energy increases enough to cause wire breakage.

Analysis of surface roughness (SR)

Fit summary for surface roughness is listed in Table 4 . Two factors interaction (2FI) model has been suggested for SR. In case of SR, value of $R^{2}$ and $R^{2}$ (adj.) is greater than $99 \%$ which shows that regression model provides an excellent explanation of the relationship between input variables and the response. The $p$ value for model is less than 0.05 , indicating that the model is statistically significant. The lack of fit is also non-significant. The input parameters $\mathrm{A}, \mathrm{B}, \mathrm{C}, \mathrm{D}$ and interaction terms $\mathrm{AB}, \mathrm{AC}, \mathrm{BD}$ and $C D$ have significant influences on surface roughness as indicated by the associated $p$ value (less than 0.05 ). Figure 3 shows the normal probability plot of residuals for SR. Residuals are falling on a straight line which means that the errors are normally distributed. After eliminating the non-significant terms, the final response equation for SR is given as follows:

In coded terms

$$
\begin{aligned}
\mathrm{SR}= & 1.66+0.13 \mathrm{~A}+0.42 \mathrm{~B}-0.12 \mathrm{C}-0.14 \mathrm{D} \\
& +0.026 \mathrm{~A} \times \mathrm{B}-0.039 \mathrm{~A} \times \mathrm{C} \\
& -0.042 \mathrm{~B} \times \mathrm{D}+0.043 \mathrm{C} \times \mathrm{D} .
\end{aligned}
$$

In actual parmeters

$$
\begin{aligned}
\mathrm{SR}= & -6.22607-1.68519 \mathrm{E}-003 \mathrm{Ip}+0.080741 \\
& \times \text { Ton }-0.027889 \mathrm{Toff}+0.31389 \mathrm{SV} \\
& +1.45833 \mathrm{E}-004 \mathrm{Ip} \times \text { Ton }-2.5833 \mathrm{E}-004 \mathrm{Ip} \\
& \times \text { Toff }-7.08333 \mathrm{E}-004 \mathrm{Ton} \times \mathrm{SV} \\
& +8.5000 \mathrm{E}-004 \text { Toff } \times \mathrm{SV} .
\end{aligned}
$$

Figure $4 \mathrm{a}-\mathrm{c}$ shows the combined effect of input parameters on surface roughness. Increasing the value of Ip and Ton increases the value of surface roughness. High discharge energy due to high value of Ton and Ip results in melting and evaporation of work material that causes formation of gas bubbles that explode when the discharge ceases. Explosion of gas bubbles causes generation of 

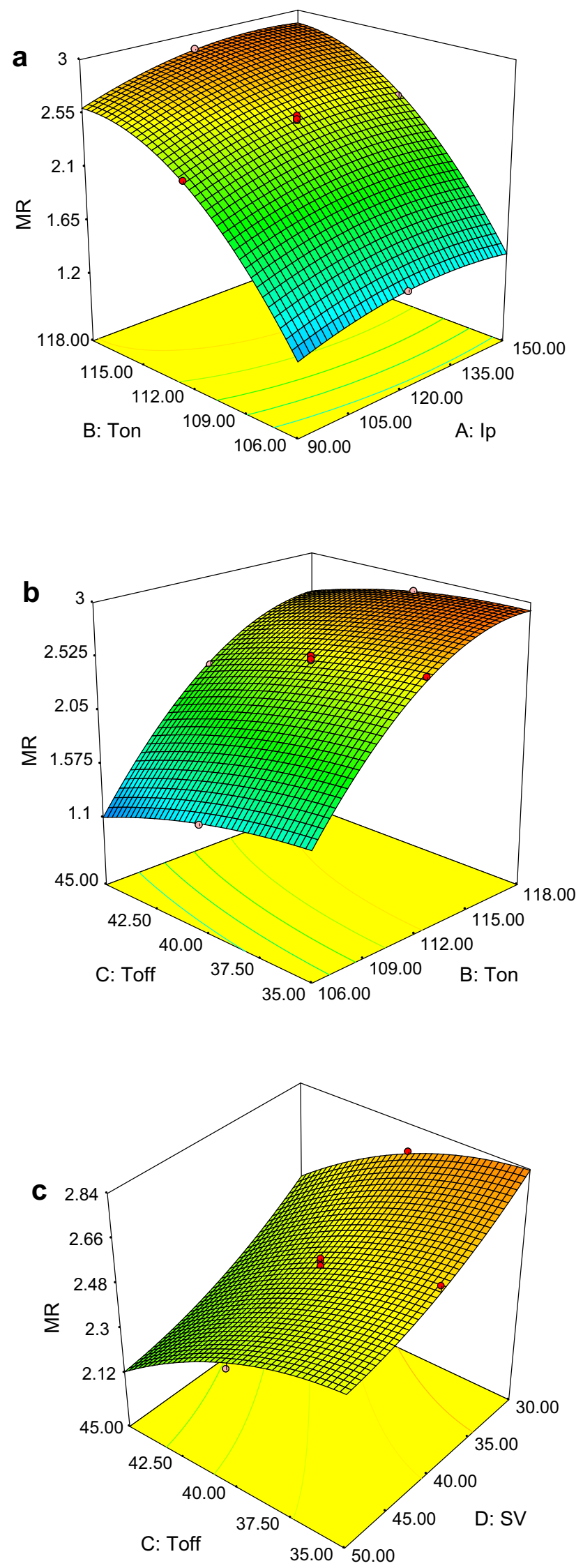

4Fig. 2 a Effect of Ip and Ton on MR at Toff: $40 \mu \mathrm{s}$; SV: $40 \mathrm{~V}$, b effect of Ton and Toff on MR at Ip: 120 A; SV: $40 \mathrm{~V}$, c effect of Toff and SV on MR at Ip: 120 A; Ton: $120 \mu \mathrm{s}$

high-pressure energy that creates large-size craters on work surface. The diameter and depth of crater increases with increasing discharge current and pulse-on time and hence increases the surface roughness (Hewidy et al. 2005). High discharge energy (Ip: 150 A; Ton: $118 \mu$ s; Toff: $35 \mu \mathrm{s} ; \mathrm{SV}: 30 \mathrm{~V}$ ) results in the formation of overlapped and deep craters with large-size diameters as shown in Fig. 5a. High density of melted globules gets accumulated at the machined surface resulting in poorer surface finish.

Increase in the value of Toff decreases the spark frequency and hence reduces the discharge energy, as a result smooth surface with small crater size is generated as shown in Fig. 5b. Increasing the Toff results in quick and easy flushing of melted debris that results in minimum accumulation of melted globules and hence decreases SR as shown in Fig. 4b. Surface roughness decreases with increasing the value of servo voltage as shown in Fig. 4c. Increasing SV increases the gap between work material and wire electrode that results in low ionization of dielectric medium and hence low discharge energy get generated. Minimum surface roughness is obtained corresponding to low discharge energy, i.e., Ip: 90 A; Ton: $106 \mu$ s; SV: $50 \mathrm{~V}$ and high value of Toff $45 \mu \mathrm{s}$.

In WEDM, the extent of surface damage depends on the discharge energy across the work surface. Figure 6 shows the microhardness profile underneath the machined surface corresponding to high and low discharge energy. It is clear from Fig. $6 \mathrm{a}$ that the microhardness reduces at the top layers of machined surface as compared to bulk material. This reduction is mainly due to the thermal energy across the work surface which increases with increasing discharge energy ( $\mathrm{Li}$ et al. 2013). Copper is a main constituent in Monel-400 which results in good thermal conductivity of Monel-400. As a result, fraction of heat transferred toward the bulk material is more as compared to other ceramics and carbide materials (Garcia Navas et al. 2008) and hence the heat-affected zone increases that lower the microhardness underneath the machined surface as compared to bulk material.

\section{Multi-performance optimization through desirability function approach}

Increasing the value of Ip and Ton and decreasing the value of Toff and SV, increases the discharge energy and vice versa. The generation of high discharge energy causes high machining rate but result in poor surface finish. Therefore, 
Table 4 ANOVA table for SR (after backward elimination)

\begin{tabular}{llllrll}
\hline Source & Sum of squares & Degree of freedom & Mean square & $F$ value & $p$ value & \\
\hline Model & 4.19 & 8 & 0.52 & 665.61 & $<0.0001$ & Significant \\
A & 0.30 & 1 & 0.30 & 383.29 & $<0.0001$ & \\
B & 3.17 & 1 & 3.17 & 4024.52 & $<0.0001$ & \\
C & 0.28 & 1 & 0.28 & 354.25 & $<0.0001$ & \\
D & 0.35 & 1 & 0.35 & 444.80 & $<0.0001$ & \\
AB & 0.011 & 1 & 0.011 & 14.01 & 0.0012 & \\
AC & 0.024 & 1 & 0.024 & 30.53 & $<0.0001$ & \\
BD & 0.029 & 1 & 0.029 & 36.73 & $<0.0001$ & \\
CD & 0.029 & 1 & 0.029 & 36.73 & $<0.0001$ & \\
Residual & 0.017 & 21 & $7.869 \mathrm{E}-004$ & & & \\
Lack of fit & 0.015 & 16 & $9.234 \mathrm{E}-004$ & 2.64 & 0.1442 & Not significant \\
Pure error & $1.750 \mathrm{E}-003$ & 5 & $3.500 \mathrm{E}-004$ & & & \\
Cor total & 4.21 & 29 & $R^{2}$ (Adj.) $=0.9946$ & & & \\
Standard deviation $=0.028$ & $R^{2}=0.9961$ & & & & & \\
\hline
\end{tabular}

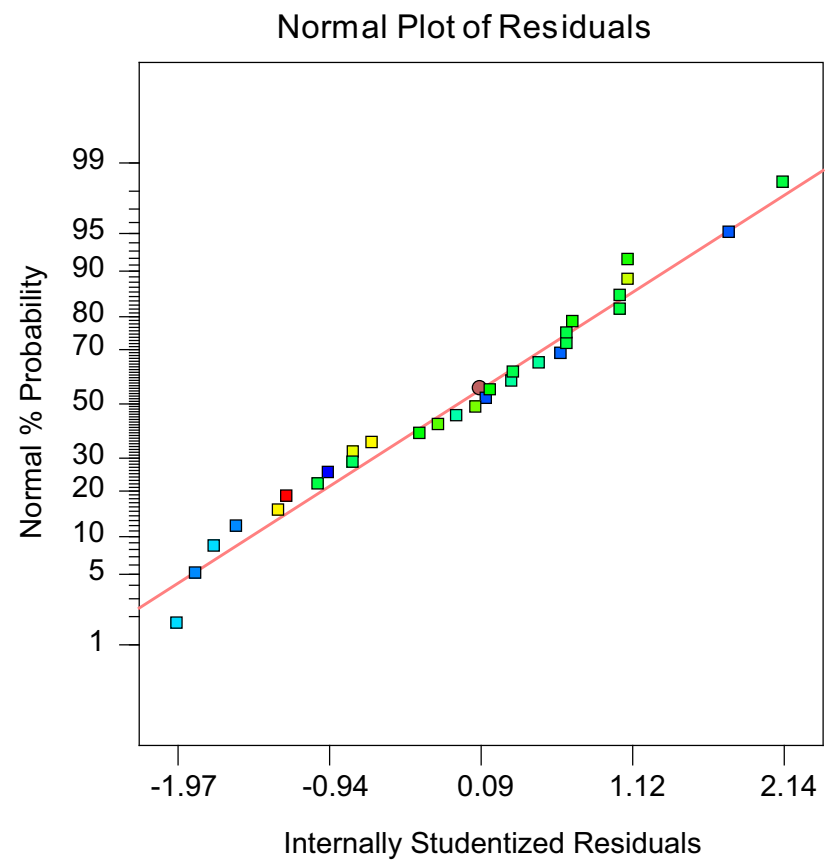

Fig. 3 Residuals plot for SR

an optimal parameters setting is needed for simultaneously obtaining higher machining rate as well as minimum surface roughness. Using desirability function, the optimal WEDM parameters setting for MR and SR has been obtained.

Derringer and Suich (1980) proposed a multiple response optimization technique approach called desirability function. The general approach is to first convert each response $y_{i}(x)$ into an individual desirability function $\left(d_{i}\right)$ and vary over the range $0 \leq d_{i} \leq 1$. The simultaneous objective function is a geometric mean of all converted responses. In the present study, design expert 7 has been used to optimize the response variables.
Derringer and Suich defined the three types of desirability function depending on the type of response characteristics as:

1. For the "larger-the-better" type:

$$
d_{i}= \begin{cases}0, & y_{i} \leq y_{i^{*}} \\ {\left[\frac{y_{i}-y_{i^{*}}}{y_{i}^{\prime}-y_{i^{*}}}\right]^{t},} & y_{i^{*}}<y_{i}<y_{i}^{\prime} \\ 1, & y_{i} \geq y_{i}^{\prime},\end{cases}
$$

where $y_{i^{*}}$ is the minimum acceptable value of $y_{i}, y_{i}^{\prime}$ is the highest value of $y_{i}$ and $t$ is the shape function for desirability.

2. For the smaller-the-better type:

$d_{i}= \begin{cases}1, & y_{i} \leq y_{i}^{\prime \prime} \\ {\left[\frac{y_{i}^{*}-y_{i}}{y_{i}^{*}-y_{i}^{\prime \prime}}\right]^{r},} & y_{i}^{\prime \prime}<y_{i}<y_{i}^{*} \\ 0, & y_{i} \geq y_{i}^{*},\end{cases}$

where $y_{i}^{\prime \prime}$ is the lowest value of $y_{i}, y_{i}^{*}$ is the maximum acceptable value of $y_{i}$ and $r$ is the shape function for desirability.

3. For the nominal-the-best type:

$$
d_{i}= \begin{cases}{\left[\frac{y_{i}-y_{i}^{*}}{C_{i}-y_{i}^{*}}\right]^{s},} & y_{i^{*}}<y_{i}<C_{i} \\ {\left[\frac{y_{i}-y_{i}^{*}}{C_{i}-y_{i}^{*}}\right]^{t},} & C_{i}<y_{i}<y_{i}^{*} \\ 0, & y_{i}>y_{i}^{*} \text { or } y_{i^{*}}>y_{i},\end{cases}
$$

where $C_{i}$ is the most acceptable or target value and $s$ and $t$ are the exponential parameters that determine the shape of desirability function.

Overall desirability function of the multi-response system can be measured by combining the individual desirability 

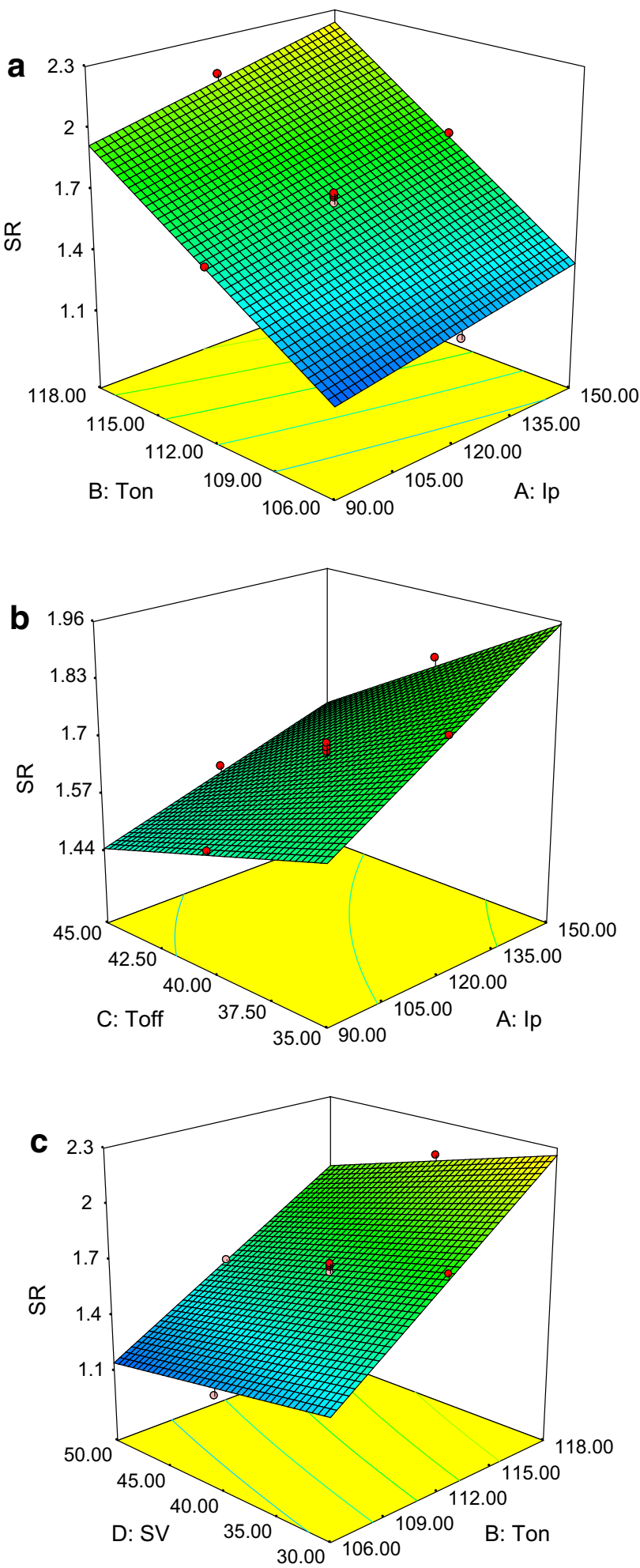

Fig. 4 a Effect of Ip and Ton on SR at Toff: $40 \mu \mathrm{s} ; \mathrm{SV}: 40 \mathrm{~V}$, b effect of Toff and Ip on SR at Ton:112 $\mu$ s; SV: $40 \mathrm{~V}$, c effect of Ton and SV on SR at Ip: 120 A; Toff: $40 \mu \mathrm{s}$
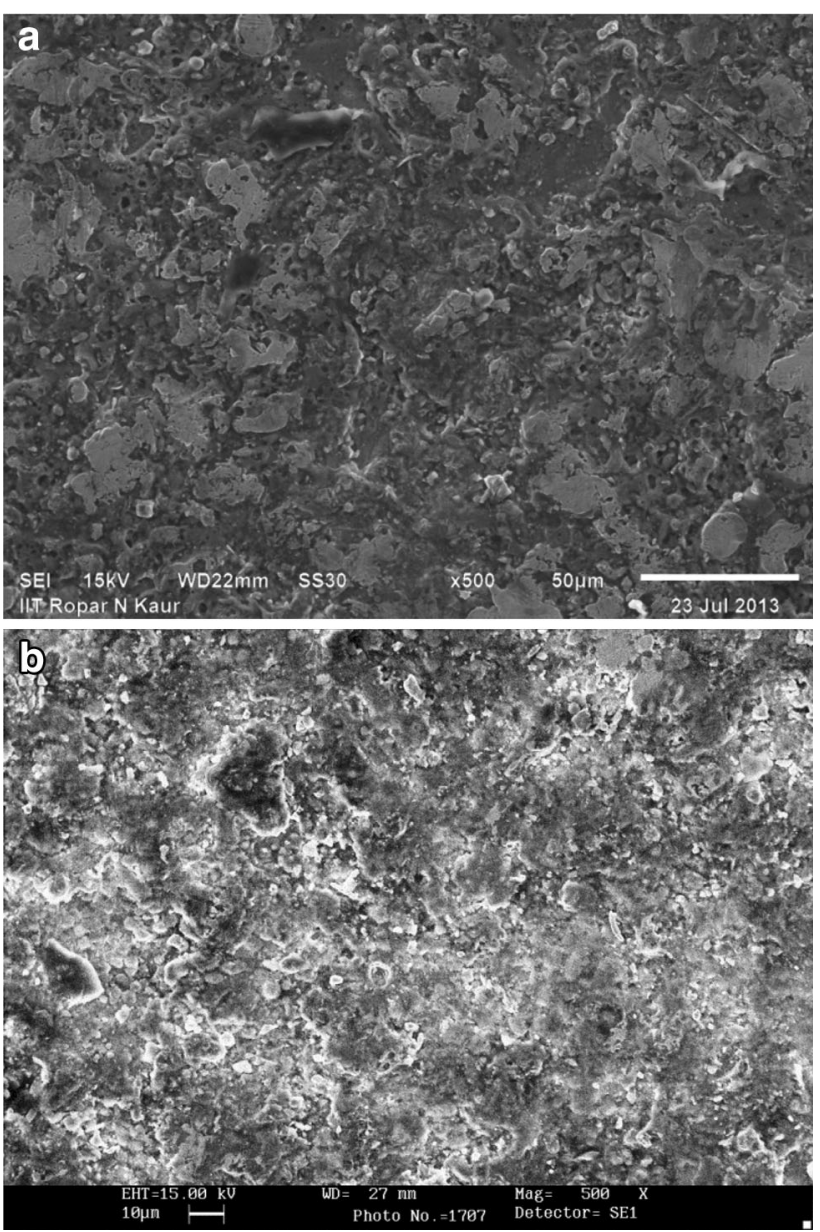

Fig. 5 a WEDM machined surface at Ip:150 A; Ton: $118 \mu$ s; Toff: $35 \mu \mathrm{s}$; SV: $30 \mathrm{~V}$, b WEDM machined surface at Ip: $90 \mathrm{~A}$; Ton: $106 \mu$ s; Toff: $50 \mu \mathrm{s} ; \mathrm{SV}: 50 \mathrm{~V}$

functions. It can be represented as $D=\left(d_{1}^{w 1} \cdot d_{2}^{w 2} \ldots \ldots d_{n}^{w n}\right)$, where $w_{j}\left(0<w_{j}<1\right)$ is the weight value given for the importance of $j$ th response variable and $\sum_{j=1}^{n} w_{j}=1$. The parameter settings with maximum overall desirability value are considered to be the optimal parameter combination.

In the present study, the goal is to find optimal parameter settings that maximize the overall desirability function for higher machining rate and minimum surface roughness value. The ranges and targets of input parameters namely Ip, Ton, Toff and SV and the response characteristics machining rate and surface roughness are given in Table 5.

Table 6 shows the possible combination of WEDM process parameters that gives the high value of desirability. Contour plots offering overall desirability for multi-performance characteristic are drawn as shown in Fig. 7. The 
Fig. 6 a Microhardness profile underneath the machined surface, $\mathbf{b}$ microindents on transverse section

Table 5 Range of input parameters; MR and SR for desirability

Table 6 Process parameters combination for high value of desirability
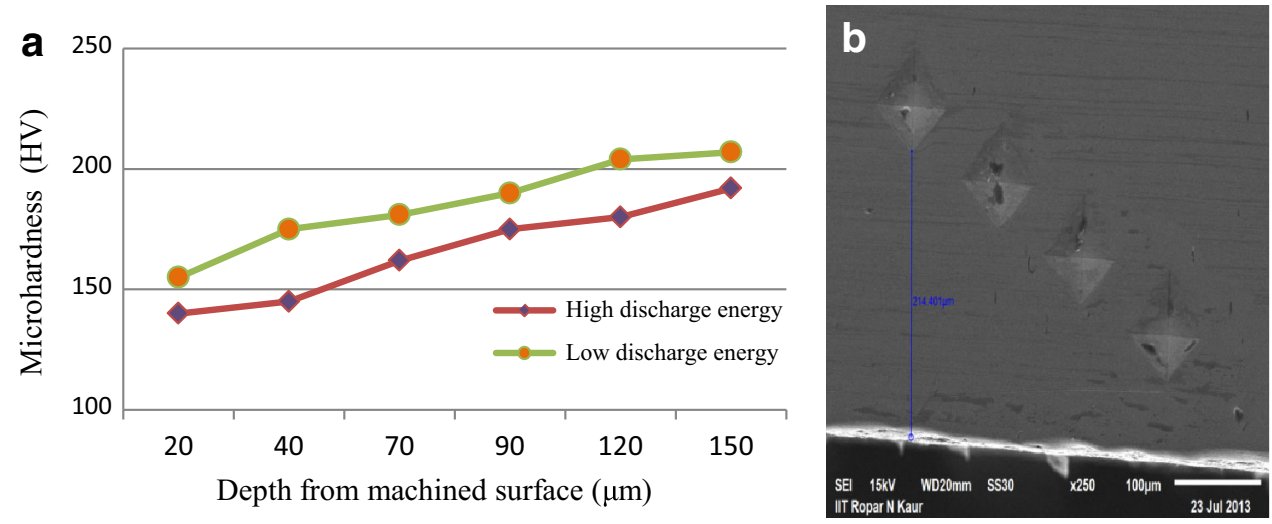

\begin{tabular}{lllll}
\hline Constraint & Goal & Lower limit & Upper limit & Important \\
\hline Discharge current (Ip) & In range & 90 & 150 & 3 \\
Pulse-on Time (Ton) & In range & 106 & 118 & 3 \\
Pulse-off time (Toff) & In range & 35 & 45 & 3 \\
Servo voltage (SV) & In range & 30 & 50 & 3 \\
MR $(\mathrm{mm} / \mathrm{min})$ & Maximize & 0.79 & 3.16 & 3 \\
SR $(\mu \mathrm{m})$ & Minimize & 0.98 & 2.60 & 3 \\
\hline
\end{tabular}

\begin{tabular}{lllllllll}
\hline \multirow{2}{*}{ Number } & \multicolumn{3}{l}{ Process parameters } & & & \multicolumn{2}{l}{ Predicted response } & \multirow{2}{*}{ Desirability } \\
\cline { 2 - 3 } & Ip & Ton & Toff & SV & & MR & SR & \\
\hline 1 & 103.20 & 112.88 & 37.14 & 50.00 & 2.48 & 1.54 & 0.68304 \\
2 & 102.73 & 112.93 & 37.17 & 50.00 & & 2.48 & 1.54 & 0.68303 \\
3 & 102.80 & 112.84 & 37.17 & 50.00 & 2.47 & 1.53 & 0.68303 \\
4 & 103.27 & 112.90 & 37.35 & 50.00 & 2.47 & 1.54 & 0.68301 \\
5 & 102.47 & 112.78 & 37.13 & 50.00 & 2.46 & 1.53 & 0.68298 \\
6 & 101.55 & 112.94 & 37.15 & 50.00 & 2.47 & 1.53 & 0.68296 \\
7 & 102.34 & 113.00 & 37.35 & 50.00 & 2.48 & 1.54 & 0.68296 \\
8 & 102.02 & 112.97 & 36.77 & 50.00 & 2.48 & 1.54 & 0.68293 \\
\hline
\end{tabular}

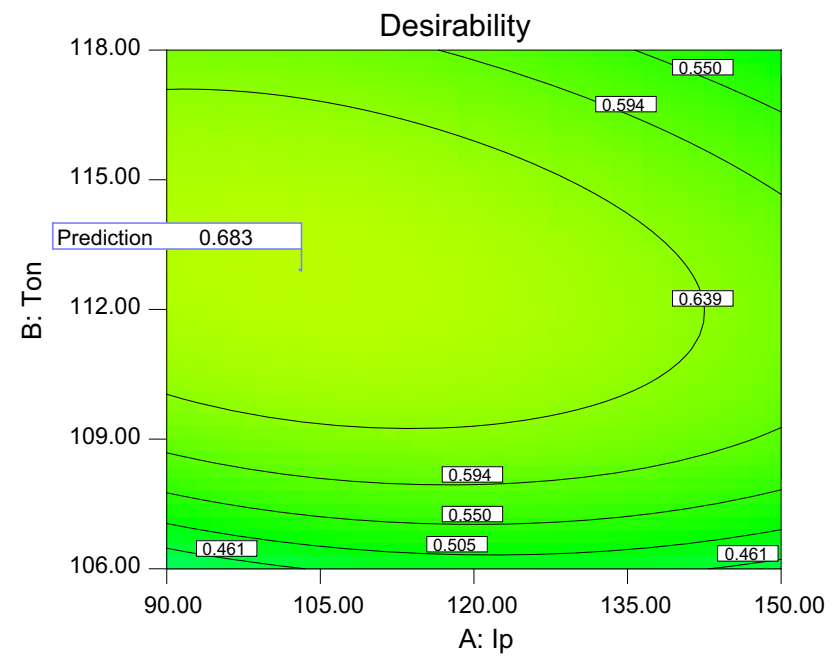

Fig. 7 Contour plot for overall desirability (Toff: $37 \mu$ s; SV: $50 \mathrm{~V}$ ) optimal region has been located near to left-hand side which has a desirability value of 0.683 that gradually reduced as we moved right and downwards. Corresponding to highest desirability, optimal combination of WEDM parameters for multi-performance characteristics is Ip: 103 A, Ton: $113 \mu$ s; Toff: $37 \mu \mathrm{s}$; SV: 50 V. Experimental values obtained corresponding to optimal setting for MR and SR were $2.65 \mathrm{~mm} / \mathrm{min}$ and $1.7 \mu \mathrm{m}$ that are closer to the predicted values in Table 6 .

\section{Trim cutting operation in WEDM}

In WEDM, trim cutting operation is used to reduce surface damage such as thickness of recast layer, micro cracks and job inaccuracies developed in rough cutting operation. Damaged surface layer can be removed using single- or 


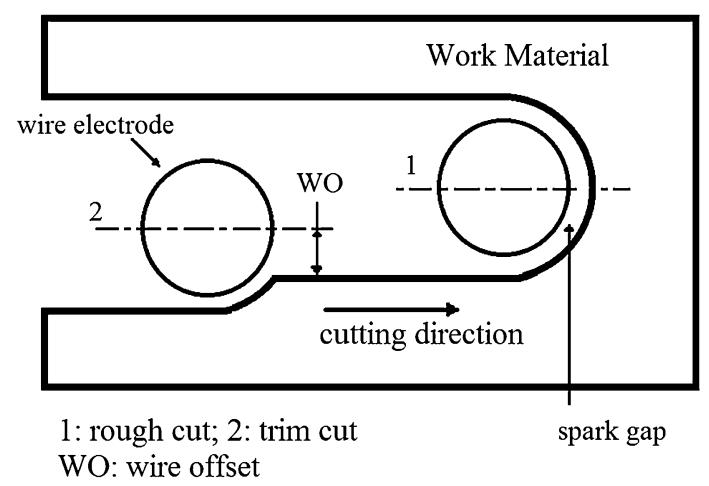

Fig. 8 Terminology used in trim cutting operation

multi-trim cuts. In trim cutting operation, wire electrode traces back the rough cut path but with some offset (Jangra 2014) as shown in Fig. 8. In the present study, trim cutting operations have been performed with two different wire offsets 105 and $85 \mu \mathrm{m}$ at constant discharge energy. In the present work, wire offset (WO) is taken as distance between center of electrode and work surface before trim cut as shown in Fig. 8.

Trim cutting operations conducted after a rough cutting operation that was performed at high level of discharge energy (HDE) correspond to the parameters shown in Table 7. In contrast to rough cutting operation, low discharge energy is required in trim cutting operation, to obtain fine surface finish. Because of low discharge energy, a laminar dielectric flow is required in trim cutting operation for effective spark generation which otherwise is not possible at high or turbulent dielectric supply as in case of rough cutting operation. Therefore, a low dielectric supply is allowed through upper nozzle while bottom nozzle is closed. Figure 9 shows the comparative influence of trim cutting operation on surface roughness. It is clear from the Fig. 9 that surface roughness has been improved in trim cutting operation after a rough cut at high discharge energy. But the effect of multi trim cuts is negligible on surface roughness. It implies that using single trim cut with appropriate wire offset value and discharge parameters, surface integrity can be improved significantly irrespective of the rough cutting parameters.

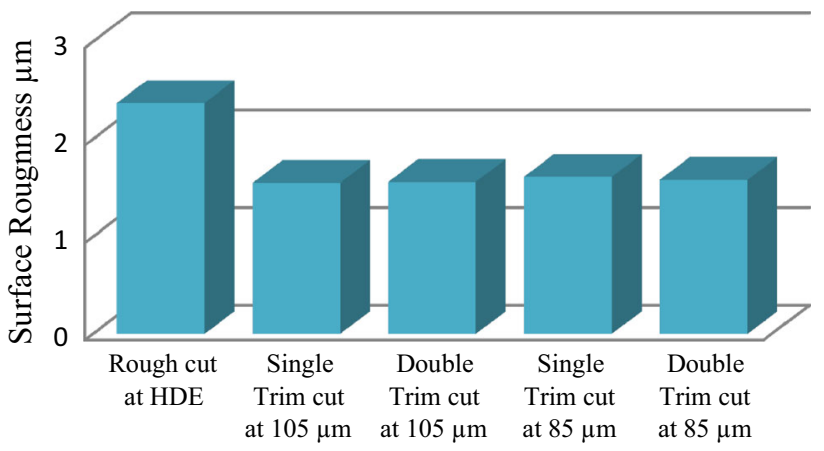

Fig. 9 Effect of trim cutting operation on surface roughness

\section{Conclusions}

This work presents the experimental study on wire electrical discharge machining of Monel-400, a nickel-copperbased alloy. Using response surface methodology and facecentered central composite design, experiments for rough cutting operation were performed to investigate and model the four WEDM parameters namely Ip, Ton, Toff and SV for two performance characteristics namely machining rate (MR) and surface roughness (SR).

Using analysis of variance (ANOVA), quadratic model is found significant for MR while two factors interaction (2FI) model has been suggested for SR. Increasing Ip and Ton increases the discharge energy that results in high value of MR but it adversely affects the SR. Increasing Toff decreases the MR but improves the surface finish by flushing out melted debris completely. Increase in SV decreases the MR and improves the SR. Microhardness profile underneath the machined surface describes the extent of thermal damage due to the discharge energy across the work surface.

Using desirability function, a scale-free quantity called desirability has been obtained for two performance characteristics to optimize multi-performance characteristics, i.e., MR and SR. Corresponding to highest desirability, the optimal combination of discharge parameters was Ip: $103 \mathrm{~A}$; Ton: $113 \mu \mathrm{s}$; Toff: $37 \mu \mathrm{s}$ and SV: $50 \mathrm{~V}$. Trim cutting operations at low discharge energy (Ton: $105 \mu \mathrm{s}$; Toff: $35 \mu$ s; Ip: 90 A; SV: $30 \mathrm{~V}$ ) and different wire offset

Table 7 Parameter setting in trim cutting operation

\begin{tabular}{|c|c|c|c|}
\hline WEDM operation & Discharge parameters & $\begin{array}{l}\text { Wire offset } \\
\text { value (WO) }\end{array}$ & Other parameters \\
\hline Rough cut & $\begin{array}{l}\text { Ton } 118 \mu \mathrm{s} \text {, Toff } 35 \mu \mathrm{s} \text {, } \\
\text { Ip } 160 \mathrm{~A}, \mathrm{SV}: 30 \mathrm{~V}\end{array}$ & 0 & $\begin{array}{l}\text { Wire diameter (WD): } 250 \mu \mathrm{m} \text {; wire tension (WT): } 10 \mathrm{~N} \text {; wire feed rate } \\
\text { (WF): } 5 \mathrm{~m} / \mathrm{min} \\
\text { Dielectric flow rate (DFR) } 12 \mathrm{LM}^{-1} \text {; servo feed (SF): } 2080\end{array}$ \\
\hline Trim cut & $\begin{array}{l}\text { Ton } 105 \mu \mathrm{s} \text {, Toff } 35 \mu \mathrm{s} \text {, } \\
\text { Ip } 90 \mathrm{~A}, \mathrm{SV} 30 \mathrm{~V}\end{array}$ & $\begin{array}{l}105 \mu \mathrm{m} \\
85 \mu \mathrm{m}\end{array}$ & $\begin{array}{l}\text { Wire tension } 8 \mathrm{~N} \text {; WF } 2 \mathrm{~m} / \mathrm{min} \text {; DFR: } 3 \mathrm{LM}^{-1} \text { (upper nozzle); } \\
\text { bottom nozzle: closed }\end{array}$ \\
\hline
\end{tabular}


values (105 and $85 \mu \mathrm{m}$ ) were performed after a single rough cut at high discharge energy. Results showed that using single trim cut at low discharge energy and appropriate wire offset value, surface integrity of work material can be improved successfully.

Authors' contribution All the three authors have equally contributed to this work. Dr. Kamal Kumar Jangra and Dr. Vikas Kumar are the research supervisors of Vinod Kumar. They contributed in conducting the experiments, writing and correction of this research article.

Open Access This article is distributed under the terms of the Creative Commons Attribution License which permits any use, distribution, and reproduction in any medium, provided the original author(s) and the source are credited.

\section{References}

Antar MT, Soo SL, Aspinwall DK, Jones D, Perez R (2011) Productivity and workpiece surface integrity when WEDM aerospace alloys using coated wires. Procedia Eng 19:3-8

Aspinwall DK, Soo SL, Berrisford AE, Walder G (2008) Workpiece surface roughness and integrity after WEDM of Ti-6Al-4 V and Inconel 718 using minimum damage generator technology. CIRP Ann Manuf Technol 57:187-190

Cochran G, Cox GM (1962) Experimental design. Asia Publishing House, New Delhi

Deringer G, Suich R (1980) Simultaneous optimization of several response variables. J Qual Technol 12:214-219

Garcia Navas V, Ferreres I, Marañón JA, Garcia-Rosales C, Sevillano J (2008) Electro-discharge machining (EDM) versus hard turning and grinding-comparison of residual stresses and surface integrity generated in AISI O1 tool steel. J Mater Process Technol 195(1-3):186-194

Herbert CRJ, Kwong J, Kong MC, Axinte DA, Hardy MC, Wither PJ (2012) An evaluation of the evolution of workpiece surface integrity in hole making operations for a nickel-based super alloy. J Mater Process Technol 212:1723-1730

Hewidy MS, El-Taweel TA, El-Safty MF (2005) Modeling the machining parameters of wire electrical discharge machining of Inconel 601 using RSM. J Mater Proces Technol 169:328-336

Hood R, Soo SL, Aspinwall DK, Andrews D, Sage C (2011) Twist drilling of Haynes 282 super alloy. Procedia Eng 19:150-155

Jangra K (2012) Study of unmachined area in intricate machining after rough cut in WEDM. Int J Ind Eng Comput 3:887-892

Jangra KK (2014) An experimental study for multi-pass cutting operation in wire electrical discharge machining of WC-5.3\% Co composite. Int J Adv Manuf Technol. doi:10.1007/s00170014-6218-4
Jangra K, Grover S (2012) Modeling and experimental investigation of process parameters in WEDM of WC-5.3\% Co using response surface methodology. Mech Sci 3:63-72

Kang SH, Kim DE (2003) Investigation of EDM characteristics of nickel-based heat resistant alloy. KSME Int J 17(10):1475-1484

Kansal HK, Singh S, Kumar P (2005) Parametric optimization of powder mixed electrical discharge machining by response surface methodology. J Mater Process Technol 169:427-436

Klink A, Guo YB, Klocke F (2011) Surface integrity evolution of powder metallurgical tool steel by main cut and finishing trim cuts in wire-EDM. Procedia Eng 19:178-183

Kortabarria A, Madariaga A, Fernandez E, Esnaola JA, Arrazola PJ (2011) A comparative study of residual stress profiles on Inconel 718 induced by dry face turning. Procedia Eng 19:228-234

Krain HR, Sharman ARC, Ridgway K (2007) Optimisation of tool life and productivity when end milling Inconel 718TM. J Mater Process Technol 189:153-161

Li L, Guo YB, Wei XT, Li W (2013) Surface integrity characteristics in wire-EDM of Inconel 718 at different discharge energy. Procedia CIRP 6:221-226

Liu HS, Yan BH, Huang FY, Qiu KH (2005) A study on the characterization of high nickel alloy micro-holes using microEDM and their applications. $\mathbf{J}$ Mater Process Technol 169(3):418-426

Myers RH, Montgomery DH (1995) Response surface methodology. Wiley, New York

Rebelo JC, Morao Dias A, Kremer D, Lebrun JL (1998) Influence of EDM pulse energy on the surface integrity of martensitic steels. J Mater Process Technol 84:90-96

Sakar S, Sekh M, Mitra S, Bhattacharyya B (2008) Modeling and optimization of wire electrical discharge machining of $\gamma-\mathrm{TiAl}$ in trim cutting operation. J Mater Process Technol 205:376-387

Sanchez JA, Rodil JL, Herrero A, Lopez de Lacalle LN, Lamikiz A (2007) On the influence of cutting speed limitation on the accuracy of wire-EDM corner cutting. J Mater Process Technol 182:574-579

Sharman ARC, Hughes JI, Ridgway K (2006) An analysis of the residual stresses generated in Inconel $718^{\mathrm{TM}}$ when turning. J Mater Process Technol 173:359-367

Shivade AS, Shinde VD (2014) Multi-objective optimization in WEDM of D3 tool steel using integrated approach of Taguchi method and grey relational analysis. J Ind Eng Int 10:149-162

Shoemaker LE, Smith GD (2006) A century of monel metal: 1906-2006. J Miner Met Mater 58(9):22-26

Soo SL, Hood R, Aspinwall DK, Voice WE, Sage C (2011) Machinability and surface integrity of RR 1000 nickel based superalloy. CIRP Ann** Manuf Technol 60:89-92

Ulutan D, Ozel T (2011) Machining induced surface integrity in titanium and nickel alloys-a review. J Mach Tools Manuf $51: 250-280$

Wei X (2002) Experimental study on the machining of a shaped hole Ni-based super-heat-resistant alloy. J Mater Process Technol 129:143-147 